\title{
Features of the perception of the world by the modern younger generation
}

\author{
Zarema Masaeva ${ }^{1 *}$, Laura Kagermazova ${ }^{2}$, and Irina Danchenko ${ }^{3}$ \\ ${ }^{1}$ Chechen State University, 364034, Grozny, Russia \\ ${ }^{2}$ Chechen State Pedagogical University, 364068, Grozny, Russia \\ ${ }^{3} \mathrm{NF} \ll \mathrm{PGU} », 353920$, Novorossiysk, Russia
}

\begin{abstract}
Today, in the era of globalization of modern society, it is important to create a favorable environment for the younger generation. The presence of fears in children at preschool age prevents favorable mental development. This paper reflects the results of a study to identify the prevailing fears in children in preschool age. According to the results of the conducted empirical research, it was revealed that there is a tendency to increase fears in children, due to individual characteristics and the present stresses, neuroticism in preschool children. The results show that preschool childhood is one of the most difficult periods, which is characterized by neurotic fears that cause a general deterioration of the child's psychoemotional state. It is very important to register the emotional changes of a preschooler, since the lack of information about the occurrence and development of fears in children causes complex barriers in the child's further development.
\end{abstract}

\section{Introduction}

One of the symptoms of neurosis in preschool children is fear. In our opinion, research in this area will help solve a number of problems of preschool children, including the difficulties of taking on new social roles in relation to the problems of adapting kindergarten to school and a number of other topical issues that face psychological science.

Research in this area is important to conduct a comparative and age-related study of borderline mental disorders in preschoolers at different stages of mental development.

The presence of fears arising from the development of the intellectual sphere and imagination is characteristic of every age. Under favorable circumstances of the child's life, such fears disappear: children "grow" out of them. However, sometimes fears interfere with the child's personal development and create adaptive, neurotic and other problems for him, and in general are a sign of trouble. In this paper, a study was conducted to identify the number of fears in preschool children aged from 3 years 8 months to 5 years 5 months using the "Children's Fears" method of A. I. Zakharov's research is aimed at identifying the frequency, content, and quantity of fears, suggesting that an increase in the number and intensity of fears correlates with the level of neuroticism.

\footnotetext{
*Corresponding author: masaeva-2009@mail.ru
} 
Every year, the number of children diagnosed with various neuropsychiatric disorders or borderline mental disorders increases. The consequences of these disorders cause problems for long years of a child's life (primary school), and then in later life significantly determine not only his state of mental and psychosomatic health (T. Fontenelle et al.), but also the features of changes. Individual traits of a child's personality (A. Kazdin, J. Rogers, L. Kolbus) affect all levels and forms of adaptation (psychological, social, and professional) $[1,2]$.

Increased attention to the study of neuroses is associated with the huge prevalence of this condition. According to the analytical review of world health sociological research in the European Union (EU), sick children with mental disorders make up a high proportion of children with non-psychotic disorders. A high percentage $(35.3 \%)$ of people with nervous diseases was identified in 1986 in the UK, in Italy this figure is $24.8 \%$, in Spain $-12.7 \%$. According to the American National Association of Mental Health, one in ten children in the United States has a disorder designated by the term "Serious emotional disorders", which is interpreted as "a group of mental disorders that includes disorders of behavior and / or thinking and / or emotions." This term refers to all violations of the neurotic register.

Statistics of the Ministry of Health of the Russian Federation indicate that in the 90s among non - psychotic mental disorders of children, the incidence increased in almost all positions: the incidence of neuroses increased by $9.7 \%$, psychopathies - by $37.5 \%$, specific symptoms and syndromes - by $38.9 \%$, reactive states-by $45.6 \%$. The incidence rates of psychosomatic disorders increased the most (by 2.1 times, which is $110.7 \%$ ).

In Kazakhstan, Abkhazia, and Azerbaijan, there are currently no national studies on the above issue, and the problem of psychological disorders in preschool age is very relevant.

This is due to the fact that at this stage the problem is little studied both at the theoretical and practical level. The main diagnostic signs of neurosis, such as functionality, reversibility of neurological disorders after the normalization of the life situation and the disappearance of psychological trauma, have been radically revised. According to some studies, recovery occurs only in $58 \%$ of cases.

The features of the manifestation of fear in childhood were pointed out by N. J. King, D. I. Hamilton, and T.N. Ollendick [3]. In most children, the fears are short-lived and usually disappear within a few months. For some groups of children, fears become a serious problem and can affect the normal functioning of a person as a whole for a long time. T.A. Danilina, V.Ya. Zedgenidze, N.M. Stepina studied the emotional reactions of preschool children, determining the age periodization of the formation and manifestation of feelings of fear in preschool age (fear of separation from parents, fear of animals, fear of the dark, fear of death) [4].

Taking into account the above, we can say that the organization of diagnostics of psychological features of fears in preschool children is quite relevant at the theoretical and practical level of providing psychological support to preschool children.

For each age period of preschool childhood, different groups of fears are inherent, which are interrelated with high anxiety and contribute to the formation of emotional instability of the preschooler, and some fears show a dynamic progression over time, while others regress. Therefore, great attention is paid to the study of fears in the scientific works of Russian scientists V. V. Stolin, J. Man, L. S. Vygotsky, V. S. Mukhina, L. F. Obukhova, V. I. Garbuzova, A. I. Zakharova, E. G. Makarova, A. S. Spivakovskaya, M. A. Panfilova, R. V. Ovcharova, Yu. L. Neimer, and others. The problem of fears in preschoolers is described in the work of A. I. Zakharov "Day and night fears in children", "How to help our children get rid of fear". The study of fear was also carried out by foreign scientists (U. James, N. Lange, K. Izard, St. Hall, 3. Freud, D. Bowlby, Rachman M., Chersworth T., Gray J., Tomkins S., Reinhold G., etc.) [5,6,7]. 
As can be seen, the study of the features of fears was carried out at the domestic and foreign level, and despite the numerous studies in this area, the problem remains insufficiently studied.

An important role is played by fear in the preschool period, firstly, it can protect against risky actions, and secondly, fears have an obstacle in the formation of the child's personality, reducing creative activity, contributing to the development of low self-esteem, isolation, uncertainty, and high anxiety. Children's fears have a pattern of manifestation of age-related features and a temporary nature.

The relevance of this study is determined by the fact that children's fears inherent in the psyche in the early period can have a negative impact on the further emotional and psychological development of the child. After all, children's fears are the source of the cause of the manifestation of neuroses and various psychological disorders, as well as for conducting a study of children's fears in this case, it will allow you to effectively organize correctional work. In this regard, it is important to contact qualified specialists in a timely manner in order to provide measures to correct the most pronounced fears in preschoolers.

\section{Materials and methods}

The study was conducted in preschool institutions of the city of Grozny. In total, 127 children took part in the study, divided into groups (22 children with an established diagnosis of neurosis, 18 children with a pre - neurotic state (established by psychological tests), 40 - with a high degree of anxiety (established by psychological tests), 47 children normally developing). The study involved 55 girls and 72 boys.

The number of children in the main groups was distributed as follows: in the group of neuroses - 18 girls, 13 boys; in the group of pre - neuroses - 8 girls, 10 boys; in the group of anxious children - 17 girls, 23 boys; in the group of normally developing children-24 girls, 24 boys. The age of the children ranged from three years to 5 years and 5 months.

This study was conducted using the following methods: theoretical analysis, conversation, testing, the method "Children's fears (A. I. Zakharova). The process of conversation with children was carried out with the recording of the observed interesting information in real two-way communication with teachers and children. The frequency of the interviews was about two months for fifteen minutes, followed by recording the responses of the children in the protocol.

The aim of the study is to identify and clarify the prevailing fears in preschool children. Diagnostics according to the method of A. I. Zakharov "Children's fears" was carried out using 22 questions, and also to get more detailed information about the content and severity of fears in preschoolers, this method was modified to include additional questions. Taking into account the interests of modern children, animated films that they watch have been added (questions about fairy-tale characters: ghosts, monsters, cyborgs, spider-Man, werewolves, wolves, mummies).

The statistical analysis of the tests was carried out using the Statistica 6.1 software for statistical calculations. The choice of a particular method of statistical analysis mainly depends on the type of scale in which the results are expressed, as well as on the number of groups used for comparison. The study used groups of four, which means that it is necessary to focus on the criteria predefined for comparing three or more groups. The method "Children's fears" is correlated with the qualitative methods and results expressed in nominal scales (types of fears, attitude to others, etc.). However, taking into account the features of the registration of results (the number of cases or mentions), based on the frequency characteristics, its parameters can be considered as an ordinal scale.

Indeed, when comparing the subjects of one parameter (for example, " medical fears "), it would be consistent to assume that the number of these fears will symbolize the severity 
of this category of fear (i.e., the category is more pronounced in a child with two medical fears than in a child with one medical fear).

Of course, such data cannot be qualified as a scale relationship, but it makes sense to recognize that the information obtained by them is sufficient to accept them as ordinal scales.

Thus, taking into account the above-described conditions, in the current study, there was a need to define a criterion for solving the task of determining the differences between 4 groups of variables reflected in ordinal scales.

The most popular and reliable criterion used in mathematical statistics for solving the above problems is the Kruskal-Wallis criterion. Of course, such data obtained will not be considered qualified for internal scales or scales of relations, but they provide the opportunity to interpret the information obtained sufficiently to designate them as serial scales.

Taking into account the above, the Kruskal-Wallace H-test was used to compare the results using the "Children's Fears" method, and the $\chi 2$-Pearson test was used for nominal scales of differences in the features of the frequency distribution, regardless of the number of groups compared. Thus, the criterion used for mathematical processing of the results ("fear of death") was the criterion of consent $\chi^{2}-\mathrm{H}$. Pearson.

\section{Results}

According to the results of a single-factor analysis of variance for the data obtained, shown in the interval scales and relationship scales, and the analysis of frequency indicators described in the method "Children's Fears", the presence of less statistically significant differences was found (table 1).

Table 1. Results of single-factor analysis of variance

\begin{tabular}{|c|l|c|c|}
\hline № & \multicolumn{1}{|c|}{ Parameter } & H-criterion & $\begin{array}{c}\text { Significance } \\
\text { level }\end{array}$ \\
\hline 1 & Medical fears & 33.46 & $\mathrm{p}<0.001$ \\
\hline 2 & Physical fears & 46.34 & $\mathrm{p}<0.001$ \\
\hline 3 & Fears related to animals and fairy-tale characters & 24.91 & $\mathrm{p}<0.001$ \\
\hline 4 & Nightmares and nyctophobia & 43.84 & $\mathrm{p}<0.001$ \\
\hline 5 & Spatial fears & 27.32 & $\mathrm{p}<0.001$ \\
\hline 6 & Social fears & 25.17 & $\mathrm{p}<0.001$ \\
\hline 7 & Total fears & 25.17 & $\mathrm{p}<0.001$ \\
\hline
\end{tabular}

Significant differences were found in the first parameter -medical fears, the H-criterion is 33.46 at a level of $p<0.001$. The number of health fears is rather slowly increased by neuroticism, and if the distribution of the "Norm" and "Anxiety" groups is close to each other, then in the future the median clearly rises, increasing the average number of health fears from 2 to 5 .

Physical fears are the next parameter with significant differences (the value of the $\mathrm{H}$ criterion, equivalent to 46.34 at $\mathrm{p}<0.001$ ), that is, there is a gradual increase in the average number of fears from zero in the group with the norm to four fears in the neurotic group at the value of the ascending range (quartile range), which is consistent with the median growth trend and even makes it more indicative in the group of "Neuroses".

After physical fears, differences were found in the parameter "Fears associated with animals and fairy-tale characters". The total number of fears of this type is insignificant, but the value of the Kruskal-Wallis test is equivalent to 24.91 at $p<0.001$, which allows us to indicate the presence of statistically significant results. The frequency values of fears associated with animals and fairy-tale characters gradually move from the normal group to 
the group with neuroses. The fear of "Nightmares and nyctophobia" also showed a statically significant difference. Statistical analysis using the H-test showed a value of 43.84 at $\mathrm{p}<0.001$, that is, there is an increase in the median values as the neuroticism of children increases-starting from zero values in the norm group and ending with an average of two fears in the neurosis group. As in the previous case, the smooth growth of the median values does not allow us to talk about differences between normal children and neurotics, although there are differences.

Spatial fears showed statistically significant differences at the level of 27.32 at $\mathrm{p}$ $<0.001$. The range of the magnitude of fear is small, in general, from zero to three, but even in this state, the data met the criteria for the admissibility of the use of Kruskal-Wallace. The analysis of the trends of differences revealed that there is already an increase in the average number of fears with an increase in the neuroticism of children, as usual - the least amount of fear in the "Norm" group (the median is zero), the largest number in the "Neurosis" group (the median is two).

The analysis of trends of differences shows that it is customary to increase the average number of fears with an increase in the neuroticism of children, as usual - the smallest number of fears in the "Norm" group (median is zero) and the largest number in the "Neurosis" group (median is zero).

The next parameter showing significant differences is "Social fears". The H-test shows significant differences at the level of 25.17 at $p<0.001$. The analysis of indicators on the median values and quartile scale confirms the pattern revealed when interpreting the results: the aggregate number of social fears increased with the growth of neuroticism, if the median number of social fears in the "Norm" group was zero, in the "Anxiety" group already one, and in the "Pre - Neurosis" and "Neurosis" groups - two and three, respectively. In this context, it is not surprising that the last synthesis and the total parameter "Total Fears", which counts the total number of fears, also gave significant differences at the level of $\mathrm{H}=25.17$ at $\mathrm{p}<0.001$.

It is not surprising that the nature of the differences again reflected the repeatedly described trend, if neuroticism increases, then the number of fears increases. According to one of the parameters of the "Children's Fears" technique, it cannot be attributed to an ordinal scale, since it has a special feature of processing and conducting.

The parameter dedicated to the fear of death was written on a binary basis - there were only two values: "yes" and "no". " Obviously, this led to a clear understanding of the parameter as a nominal scale, which indicates the need to determine the differences in the fear of death between groups using the $\chi 2$-consent criterion. Pearson's

The calculation of Pearson's22-test showed significant variations in the distribution of the division trait between the four groups -7.75 at $p=0.5$. The analysis of the results reveals the specifics of this deviation.

A comparison of the expected and empirical distribution of the fear of death from the "Norm" group and the "Anxiety" group shows that there is practically no difference between them, in both directions, the number of cases with no fear of death is greater than the number of cases with the presence of fear of death. Apparently, significant indicators of $\chi 2$ are formed due to differences in the distribution of the other two groups.

Indeed, it is in the "Neurosis" and "Pre-Neurosis"

groups that a different frequency direction is observed when comparing the expected and actual values.

So, according to the results, it can be stated that if in the "Norm" group the number of cases of absence of fear of death is significantly greater than the presence, then in accordance with neuroticism, the situation changes in the opposite direction. 


\section{Discussion}

The results of the study allow us to state that there is a tendency to increase the number of children with fears. The reason lies in the individual characteristics and is not only in the individual characteristics of children, but also in the existing stresses, neuroticism in preschoolers $[8,9]$.

The study revealed the main fears in children of different age groups. Children aged 3 years and 8 months to 5 years have socially mediated fears (fear of loneliness, punishment, darkness, fairy-tale characters, medical fears (pain, injections, doctors, hospitals)).

Children from one and a half years and up to five years old have the following fears: nightmares, fear of illness, fear of punishment, fear of death, etc. There is an increase in "social fear" (fear of war, natural disasters, etc.), although they were not previously characteristic of this age. If the number of fears is greater than normal, then the neurotic type has a state of mental overstrain, stiffness and the need to find support. In the behavioral sphere, there is a passive state: risk avoidance in a new situation, the disappearance of curiosity.

Thus, we can say that there is a significant degree of hypersensitivity to the fears of neuroses in all age groups. These findings are consistent with the study of A. I. Zakharova, who shared the fears of day and night and pointed to the increased sensitivity of preschoolers to sudden pain and stress, loneliness and the disappearance of adult care, that is, everything related to family conflicts, A. S. Sarzhanov and A. K. Egenisova claim that fears appear in $40 \%$ of children depending on personality traits (anxiety, hypochondria, pessimism, self-doubt, dependence on other people, etc.). The main reason for the emergence of fears, according to a number of scientists, is children's fantasies to which each child reacts in a peculiar way.

Confirmation of the result is a study that compares the number of fears in preschoolers. In the group of children with neuroses and pre-neuroses, the most pronounced are: fears of fairy-tale characters (fear of monsters, mummies, etc.) in $100 \%$ of cases in girls and in $87 \%$ of cases in boys. In children with a high degree of anxiety, such fears account for $70 \%$ of cases of girls and $50 \%$ of cases of boys.

L. S. Hakobyan believes that the content of social fears experienced by children is changing, pointing out that children have new types of fears: negative characters of the new generation have changed to modern characters of horror films, and also stressed that children have a new fear of terrorists, which is observed among modern children $[10,11]$.

The results of an empirical study show that children of our time have fears that were not observed in their peers of the last century.

In groups of children with neuroses, there is a feeling of fear when considering scary children's toys $(87.5 \%)$ among girls and boys $(39 \%)$ of cases. This is due to the fact that there is a process of computerization of society as a whole, providing access to information to children through the media about various disasters: accidents, destruction, horror films, catastrophes. These circumstances form a modern psychological reality in children, contributing to the appearance of mental overstrain, anxiety in children.

Russian psychologists in the field of psychology Yu. V. Fesenko and V. I. Garbuzov revealed children's fears through the consideration of mental trauma and its role in the development of painful conditions. The source of children's fears V. I. Garbuzov considered the awareness of his death most often during the completion of preschool childhood, that is, children's fears are a manifestation of the fear of death. In this study, in groups of children with neurosis and pre-neurosis, there is an increase in the fear of death in $63,6 \%$ and $50 \%$ of cases, respectively. This type of fear is the most stable, and also undergoes a longer corrective effect [12]. 
However, according to E. A. Zakharov, it is impossible to completely overcome the fear of death in children, since it is transformed into the fear of death of parents. In our study, in the group of children with neurosis and pre-neurosis, the fear of death of parents is present in girls $-100 \%$ of cases, and in boys- $91 \%$. Children who were examined from the anxiety group showed statistics ( $88 \%$ - in girls and $52 \%$ - in boys) $[13,14,15]$.

The results of the conducted empirical study show that among preschool children in groups of children with neuroses and pre-neuroses, the fear of the dark tends to increase$100 \%$, in girls and boys- $91 \%$; the fear of dreams in children of the same groups shows in girls $-87.5 \%$ and in boys $-70 \%$. In children from the "Anxiety group" there is a decrease, but the above-mentioned fears are observed in girls- $76 \%$ and $56.5 \%$ - boys.

By dreams of fear, we should understand terrible, frightening dreams. In the scientific literature, they are called "night terrors" (Pagel, 2000) because of the sudden awakening of the child, often accompanied by crying, anxiety, tachycardia, dilated pupils. The first episodes of nightmares are usually recorded at the age of 3 years - 6 years.

Long-term fears and anxieties: fear of death, fear of changes in life (moving home, divorce of parents, change of kindergarten, etc.) lead to stressful states of the child. Hence, there is an atypical behavior for them, which manifests itself in increased aggressiveness, regression in development, health problems, and the symptoms can be so severe that it causes physical pathology, which is directly related to psychosomatics: fatigue and sleep disorders, impulsivity. This happens when the power of emotions reaches such a degree that it leads to a violation of development, deviation. Perrez stated that the physiological and mental characteristics of children, as well as their social environment, the features of events contribute to the appearance of difficult emotional reactions [16].

Taking into account the age characteristics of children, fears manifest themselves in a peculiar way, depending on the characteristics of growing up and the development of the child. Fear is favorable when performing certain functions for a short time, but if the fear does not leave the person for a long time, a psychoneurotic state may occur in the child, which can lead to a neurosis of fear and a pathological condition.

A child of the first year of life has a primary emotion of fear of strangers under the influence of a strong stimulus.

At the age of three, the child has a fear of animals and the dark, increasing until the age of four. Some scientists believe that in the preschool period, imaginary fears dominate over real fears. In the following years, children experience a decrease in imaginary dangers and an increase in real dangers.

Issues related to strong fears are the most studied and significant, and also cause controversy. Currently, a large number of fear theories have been developed, each of which is confirmed by experimental or clinical studies. These studies allow us to identify some theoretical positions. The scientist Bowlby believes that the cause of fear is mainly the presence of a threat and the lack of a sense of safe space. K. E. Izard divided the causes of fear into internal and external.

The reasons for many fears, according to A. M. Prikhodan, are external sources of fear in different periods of life, the features of the accumulated emotional experience of children's anxiety at different age levels, the influence of age-related intrapersonal characteristics that determine the occurrence of anxiety and fear in children into three groups: real (a threat to the health and well-being of the individual), imaginary (not objectively threatening the individual, but perceived by it as a threat to well-being, prestigious (the threat of loss of authority) [17].

Pathological nightmares, that is, a neurosis of fear that quickly appears and is not associated with fear or strong unmotivated anxiety. The occurrence of this feeling in the child does not leave him during the day, remaining for a long period of time (a week, a month, etc.). Quite often they experience oppressive, unpleasant sensations in the heart. 
In most cases, in young children, infantile children, in children with intellectual disabilities, the appearance of a neurosis of fear is observed. This circumstance causes a completely new stimulus (a dog attack, a sharp sound, a sudden bright light, a terrible mask, etc.). At the time of the appearance of fright, children have a short-term stupor state with mutism or trembling with sharp excitement. After that, there is a fear of a frightened person, which can provoke the loss of acquired skills in children. Of course, this study has a methodological limitation, since the study is based only on the child's responses, and parents were not investigated on the knowledge of their children's fears. Meanwhile, P. Muris et al. (2001), a study of children and their parents found that $26.7 \%$ of children did not report any nightmares, and their parents reported a much smaller number of their children's nightmares. According to parents, only $34 \%$ of children had nightmares at the age of 4-6 years. However, as for the causes of fear, the only significant difference between the responses of children and parents about the origin of nightmares was that children were more likely to mention negative information on television than their parents $[18,19]$.

This is confirmed by the results of the study, which confirm that among preschool children in the group that can be called "Normal", age-related fears are presented that are characteristic of this age and are not maladaptive: punishment is $50 \%$ of girls, $40 \%$ of boys. It should also be noted that there is a small amount of fear of space (height, water, enclosed space) in girls $-20 \%$, in boys $-10 \%$.

As a result of the data obtained, it can be said that most of the experiences of fear are inherent in the gender difference of girls in the preschool period. At the same time, at this age, they show mainly physical fears. Recently, there has been a trend towards an increase in socially mediated fears in preschool children (fear of the expected, uncertainty in the future, lack of funds), that is, these circumstances occurring at the state level prevent the provision of a favorable atmosphere that creates a comfortable environment and full mental development of the child [20, 21].

Based on the conducted theoretical, methodological and empirical research, it can be concluded that fear is perceived as a complex phenomenon that has various forms and degrees of occurrence, and does not determine an unambiguous understanding can have both positive (mobilizing) and negative (destructive) effects on the child's development.

The findings suggest that there is a link between the amount of fear and the child's neurotic state. Fear is an indicator of various neuropsychiatric disorders.

In the context of a child's mental health, fear can be understood as an autonomous painful state on the basis of which another neuropsychiatric disease may arise.

The results obtained in the course of the study can be used to model the strategy of psychocorrective work to optimize the mental development and activity of preschool children aged three to six years.

\section{Conclusion}

The results obtained allow us to conclude that preschool age is one of the most difficult age periods in which neurotic fears can appear, which subsequently worsen the emotional state of children.

The study of fears in children in preschool periods is important for revealing age-related patterns of the development of the emotional background, as well as the formation of emotional and personal structures.

It is very important and necessary to fix emotional fluctuations in preschoolers, since the lack of understanding of the causes of fear, its features of development, transition to other states often cause difficulty in understanding what is happening to the child and determining the true motives for his actions, which causes complex barriers in the organization of correctional work aimed at supporting the child. The detected fears need to 
be corrected, since there is a possibility that preschoolers who have been exposed to fear and anxiety may become the object of adult anxiety and fear after a certain time. In addition, it is important to understand that the organization of early help for children to overcome fears will have a safe and positive life in their later adult life.

\section{References}

1. L. Fontenelle, C. Marques, E. Engelhardt, M. Versiani, The Journal of Neuropsychiatry and Clinical Neurosciences 13, 508-510 (2001).

2. V.I. Garbuzov, Y. Fesenko, Neuroses of children (Publishing house "Karo", SPb,2013)

3. D.N. Barinov, Psychology and psychotechnics 9(72), 942-951 (2014).

4. M.V. Barbarisova, G.R. Shagivaleeva, Modern high-tech technologies 7(2), 195 (2013).

5. N.A. Kostyleva, T.G. Shkatova, Mat. scientific and practical conference "Readings of Ushinsky" 273-276 (2017)

6. E.G. Shevyreva, Modern education: traditions and innovations 4, 107-114 (2017).

7. K.A. Anushchenkova, M.A. Khmelkova, Children's fears in the senior preschool age and methods of their correction. The subject of knowledge, activity and communication in a changing society, Materials of the All-Russian Scientific and Practical Conference of Students, undergraduates, postgraduates and Young Scientists 18-20 (2015)

8. V.A. Polikarpov, H. Kharbor, O.V. Piskunovich, Fears of Belarusian and Iranian children in the senior preschool age, Psychology and pedagogy in the system of humanitarian knowledge, Materials of the XVII International Scientific and Practical Conference. 54-55(2015)

9. G.R. Akchulpanova, R.K. Valeeva, Academic Journal of Western Siberia 5, 4-5 (2012).

10. K.A. Petrenko, N.V. Koblova, Fear as a weakness and as a resource, III International scientific and Practical Conference "Modern Trends and Innovations in Science and Production". Mezhdurechensk 334-335(2014)

11. V.G. Dobrovolskaya, Fears in preschool age and their correction, Sat. mat. XIV-th International Scientific and Practical Conference. Ed. by E. M. Mosolov. 16-26 (2016)

12. H. Denis, Encephale-revue de psychiatrie clinique biologique et therape utique 41, 323-331 (2015).

13. D.F. Novoselova, Undergraduates and postgraduates. 536-538(2020)

14. E.G. Shevyreva, Bulletin of Science and Practice 4 (1), 352-356 (2018).

15. V.G. Dobrovolskaya, Actual aspects of the humanities 4 (4), 7-11 (2016).

16. E.E. Malkova, Anxiety and personal development (Publishing house A.I. Gerzen RGPU, St. Petersburg, 2013)

17. D.M. Dio, C.D. Frith, Nature Reviews Neuroscience 68-77 (2006).

18. G. Cacciotti, J.C. Hayton, ERC Research Paper (2014)

19. A. Olsson, K.I. Nearing, E.A. Social Cognitive and Affective Neuroscience 2 (1), 3-11 (2007). doi: 10.1093/scan/nsm005.

20. A.S. Sarzhanova, A.K. Yegenisova, Journal of Modern High Technologies 7, 155157(2013).

21. V.M. Delyagin, Russian Medical Journal 16, 822 (2012). 